\title{
Towards energy transition: conjoint assessment of large-scale PV system performance and interconnection impacts in isolated microgrid
}

\author{
Zen L. Chai ${ }^{1}$, S.P Ang ${ }^{1}$, A. Khalil ${ }^{1}$, M. A. Salam ${ }^{2}$, W. Z. Wan Hasan ${ }^{3}$, William Voon ${ }^{4}$ \\ ${ }^{1}$ Electrical and Electronic Engineering Programme Area, Universiti Teknologi Brunei, Brunei Darussalam \\ ${ }^{2}$ Department of Electrical and Computer Engineering, The University of Western Ontario, Canada \\ ${ }^{3}$ Department of Electrical and Electronic Engineering, Universiti Putra Malaysia, Malaysia \\ ${ }^{4}$ Berakas Power Management Company Sdn Bhd, Brunei Darussalam
}

\section{Article Info}

\section{Article history:}

Received Sep 13, 2019

Revised Jul 12, 2020

Accepted Jul 14, 2020

\section{Keywords:}

Hybrid microgrid

Solar photovoltaic system

performance

Time-series power flow

Short-circuit analysis

Dynamic transient stability

Multi-objective optimization

\begin{abstract}
Environmental, energy security and electricity demand concerns stimulate solar-grid integration. However, intermittent, non-dispatchable PV characteristics may challenge passive grid operation. This paper contains the comprehensive planning and assessment of a $2 \mathrm{MWp}$ CdTe-based PV system deployment proposed for hybrid operation in an isolated $11 \mathrm{kV}$ 10-bus microgrid in Brunei. The presented approach combinedly assesses PV system performance and scenario-based interconnection impacts based on a detailed PV system model considering deployment conditions. Various interconnection points with multiple sets of feeder-specific measured load profiles are examined. Results show the PV system designed for maximum annual generation achieves performance ratio of $90.6 \%$. While time-series power flow assessment reveals grid operation enhancement, there are concerns at times of generation-demand mismatch requiring proper genset sequencing and reactive power management. Meanwhile, faster relay operating time and reverse fault current are demonstrated in existing protection scheme. Dynamic grid stabilities are preserved in various generation intermittency and loss events, including the most challenging condition of further inertia and spinning reserve reduction reaching a frequency of $96.02 \%$. Finally, optimal interconnection point fulfilling multiobjectives on losses, voltage profile and line reserve capacity is identified. The findings indicate a good prospect of the synergy for advancing energy transition. The analysis could facilitate RE planning and policymaking.
\end{abstract}

Copyright (c) 2020 Institute of Advanced Engineering and Science. All rights reserved.

\section{Corresponding Author:}

Zen L. Chai,

Electrical and Electronic Engineering Programme Area,

Universiti Teknologi Brunei,

Jalan Tungku Link Gadong BE1410 Brunei Darussalam.

Email: zenl.chai@outlook.com

\section{INTRODUCTION}

Climate change is a subject of broad interest as it concerns every single creature on Earth. Paris Agreement was endorsed by most countries, including the Association of Southeast Asian Nations (ASEAN), aiming to limit the world's temperature rise for combating the threats of climate change [1]. ASEAN consists of ten developing countries, namely: Brunei Darussalam (Brunei), Cambodia, Indonesia, Laos, Malaysia, Myanmar, Philippines, Singapore, Thailand, and Vietnam. Nevertheless, the effort on carbon intensity reduction shall be boosted to achieve the aim [2]. The global electricity generation is primarily relying on non-renewable resources. Similarly, ASEAN is largely dependent on fossil fuels, resulting in electricity sector emitting the most carbon dioxide in the region [3]. In Brunei, oil and gas dominate the electricity generation mix at $99.95 \%$ [4]. Besides, fossil fuels are depleting rapidly. Brunei's oil and gas reserve estimation in [5] indicates the urgency of improving the sustainability of the energy future. Moreover, global 
electricity demand is mushrooming. Specifically, a $4 \%$ average annual increment is forecasted for Brunei [6]. Thereby, the approaching necessity for generation capacity expansion is foreseeable.

Within this context, the energy transition is taking place globally, intending to reshape the present electricity generation landscape. Renewable energy (RE) system integration into the power system is increasing in capacity and quantity. Notably, ASEAN is committed to achieving 23\% RE by the year 2025 [7]. For Brunei, 10\% RE in the electricity generation mix is targeted by the year 2035 [4]. Despite the availability of various renewable resources in ASEAN, their exploitation is relatively minimal [8]. Understanding the benefits and characteristics of the RE system could encourage wider utilization. Solar photovoltaic (PV) gains a wide interest universally, given its cost reduction and technological improvement. It has emerged as a significant source in the generation landscape. Likewise, the demand for PV products is increased in ASEAN [9]. The PV system is envisaged as a key RE system in the energy transition. The works examining the benefits and economic feasibility of the PV system in the ASEAN context are developing in recent years [10-15]. Further widespread of the PV system in ASEAN requires more research and development [16].

The energy generation of the PV system is influenced by many variables ranging from climate, installation to system components. A considerable number of studies have been undertaken aimed at analyzing the variables. Bhakta and Mukherjee [17] evaluated the performances of a proposed PV system at different geographical locations. Quansah et al. [18] performed an investigation with different PV cell technologies and revealed their distinctive performances under a similar climate. Lu and Zhao [19] examined the effect of PV panel tilt angle on dust accumulation and the impact on the generation. Yilmaz and Dincer [20] studied the relationship between system generation and losses with inverter capacity. Kumar and Sudhakar [21] analyzed the actual performance of a 10 MW PV system at Ramagundam, and interestingly, it was found to be in close agreement with simulation results. As such, detailed information such as solar resource is needed for appropriate system design and planning [22, 23]. Furthermore, a comprehensive PV system model considering deployment conditions is essential for accurate performance assessment. It is worth highlighting that dissimilar to the arid region, ASEAN shares a tropical climate with many clouds and rains throughout the year, which greatly impacts the PV system operation. Hence, it is crucial to evaluate the corresponding PV system performance for facilitating the understanding of prospective stakeholders and better planning.

It should be emphasized that the PV system, unlike conventional generation sources, possesses intermittent and non-dispatchable operating characteristics. Meanwhile, most existing grids are designed with consideration of dispatchable generation sources only. Consequently, substantial PV system penetration may disrupt the usual passive grid operation and pose challenges to the secure operation of the grid. The impacts of solar-grid integration have emerged as an active research area of broad interests within academia and industry. There have been extensive researches employing various models and scenarios in examining a variety of grid parameters. Previous researches highlighted the benefits, such as better power quality [24], peak demand shaving [25], and stability improvement [26, 27]. Kenneth and Folly [28] investigated steadystate grid operation pertaining to hypothetical PV injection levels in a 16-bus grid. In the study, the timevarying nature of generation and demand was not accounted. Hence, the grid behavior at other points in time was uncertain. Meanwhile, Nadeem Khan et al. [29] argued the significance of considering the variations, which is practiced in our present study. Baharin et al. [30] attempted simulating the impact of installing a 4 $\mathrm{kWp}$ PV system unequally at each phase of 55 load points in a typical IEEE European power grid. The change in power flow direction and breaching of statutory voltage limit between 10:00 hour and 16:00 hour were discovered. Based on the PV system generation specified from installation capacity and solar radiation information, Tévar et al. [31] conducted a power flow study in the viewpoint of potential rooftop PV panels integration in a Spanish power system. The negative impacts due to high PV penetration levels were reported, whereby surpassing $20 \%$ of maximum possible capacity infringed voltage limit whereas above $30 \%$ caused overloading and increased losses. Meanwhile, Hou et al. [32] simulated cases in a Swedish network wherein each house is installed with a PV capacity equivalent to its peak demand or offsetting annual demand. The PV system output was scaled proportionally from an existing small system. In contrast with [31], the study revealed the initial technical challenge was a limit violation of line loading instead of voltage. Athari et al. [33] performed a comparative study based on a modified 12.66 kV IEEE 69-bus grid and demonstrated the relationship of PV system allocation with grid losses and limit violations. Kumar et al. [34] carried out an optimization study focusing on achieving minimum losses and maximum voltage stability with optimal PV system siting in a 33-bus grid.

Besides, Barsoum and Lee [35] executed a sensitivity study examining protective relay operation in a hypothetical 10-bus power grid with the PV system under normal grid operating conditions. Another study by de Marco et al. [36] investigated protection system operation during fault conditions in a small PVintegrated network. Furthermore, Feilat et al. [37] and Kumar et al. [38] analyzed the impacts on dynamic 
grid security for Jordan and Kiribati, respectively. It is acknowledged from the literature that solar-grid integration may bring about contrasting impacts on wide aspects of grid planning and operation. This depends on the characteristics of PV system and grid such as time-varying generation and demand profiles, components' specifications and interconnection points, which are varied across different systems. It should also be mentioned that each country adopts a specific grid code for compliance. In this regard, a detailed technical interconnection assessment is imperative for reflecting realistic impacts.

From the literature review, there were no comprehensive studies undertaken focusing on examining the interconnection impacts from different technical aspects accounting PV system and grid characteristics in the Bruneian context. This paper seeks to contribute an in-depth analysis from the perspective of planning and assessing a large-scale PV system deployment proposed for hybrid operation in a Bruneian microgrid. Next, there is a lack of interconnection impact assessment in relation to actual load profiles and a detailed PV system model with an understanding of the system performance. Our study presents an approach of creating a linkage between PV system performance evaluation and interconnection impact assessment based upon a detailed PV system model considering deployment conditions. It delivers more complete and representative analysis and furnishes clear knowledge of the PV system design and specification yielding the outcomes under the specific conditions. In most earlier works, electricity demand modeling either had not considered multiple load profiles, hence neglecting variabilities described by other profiles or had not utilized measured load profile respective to each point-of-interest or both. Our present study examines various interconnection points incorporating multiple sets of feeder-specific real metered time-series load profiles. It enables realistic projections of the grid operation with respect to demand variations and visualization of the extent and frequency of operation state across load profiles. Moreover, a comparative study between interconnection points at different feeders, demonstrating the precise effect of locational dependence of interconnection impacts, could be rendered.

In this paper, a conjoint assessment is presented covering the performance of a $2 \mathrm{MWp}$ cadmium telluride (CdTe)-based PV system and scenario-based interconnection impacts in an isolated microgrid considering normal and extreme conditions. The impacts are assessed from time-series power flow, shortcircuit and dynamic transient stability aspects. Additionally, the optimal PV system placement in the grid is identified for loss minimization, voltage profile enhancement, and line reserve capacity improvement. An accurate model of a real $11 \mathrm{kV} \mathrm{10-bus} \mathrm{microgrid} \mathrm{in} \mathrm{Brunei} \mathrm{is} \mathrm{taken} \mathrm{as} \mathrm{the} \mathrm{test} \mathrm{system.} \mathrm{The} \mathrm{integration}$ challenges lie in the fact that the grid is a small stand-alone system without possible external interaction and fully energized by conventional generation sources. The interconnection is envisioned to be pioneer deployment for the microgrid and an integral part of Brunei's energy transition. Insights on the PV system performance and grid operation could facilitate RE planning and policymaking. The study is beneficial to researchers, utilities and policymakers in preparing for the proliferation of grid-connected PV systems.

The remainder of this paper is organized as follows. In Section 2, the models and variables utilized in the study, along with the approach are described. Section 3 contains the results and discussion on the system performance and interconnection impacts, including the identification of the best PV system placement in the grid. Finally, this paper concludes the findings with recommendations and future work.

\section{METHODOLOGY AND MODELING}

Given the background, the present study will commence by conducting a solar resource assessment for benchmarking and characterizing the meteorological condition. Utilizing the data, the corresponding hourly potential generation of the PV system designed will be computed, and the system performance will be evaluated in terms of performance indices. The analysis will proceed with scenario-based modeling of the PV system integration in the microgrid. Then, the impacts of the interconnection on the steady-state grid parameters are assessed with respect to time-varying generation and demand. In the next step, the reliable and secure operation of the PV-integrated grid is examined with regard to the protection scheme and dynamic stability under various critical operating conditions and disturbance events. The study is followed by determining the optimal PV system placement in the grid using a multi-objective performance index.

\subsection{Meteorological condition}

Solar resource potential provides a useful indication concerning the suitability of a location for PV system deployment. In this study, Meteonorm software package is utilized in deriving meteorological data including global horizontal irradiance (GHI), ambient temperature (Ta), precipitable water and air mass pressure, up to one-hour temporal resolution for all days in a year. Meteonorm is a specialized meteorological software package built upon well-developed calculation models with a database of long-term measurements at weather stations, satellites, and aerosol climatology [39]. The solar irradiation and temperature measurements are corresponding to the years 1991-2010 and 2000-2009, respectively. Based on Meteonorm, the annual GHI of Brunei and other locations in ASEAN are presented in Table 1. The relative percentage shows the annual GHI compared to the global benchmark represented by the Sonoran Desert in Arizona,

Towards energy transition: conjoint assessment of large-scale PV system performance ...(Zen L. Chai et al) 
United States [22]. From the comparison, it is noted that the annual GHI in ASEAN exhibits a promising precondition for the deployment. Specifically, Brunei receives a higher amount of solar irradiation than other ASEAN cities viz. Jakarta, Kuala Lumpur, Manila, Singapore, Bangkok, and Hanoi. Hence, it is hypothesized that the PV system will work with desirable performance in Brunei.

The geographical coordinate of the site specified for the PV system deployment is $4.7^{\circ} \mathrm{N}$ and $115.1^{\circ} \mathrm{E}$. Correspondingly, the annual total GHI and mean Ta are determined to be $1,816.6 \mathrm{kWh} / \mathrm{m}^{2}$ and $27.4^{\circ} \mathrm{C}$, respectively. Figure 1 illustrates the monthly variations of total GHI and mean Ta. The maximum monthly GHI is $171.2 \mathrm{kWh} / \mathrm{m}^{2}$ in March whereas the minimum is $138.0 \mathrm{kWh} / \mathrm{m}^{2}$ in February. Meanwhile, the monthly mean $\mathrm{Ta}$ is the highest at $28.2^{\circ} \mathrm{C}$ in May while that of the lowest is $26.9^{\circ} \mathrm{C}$ in November. The GHI and Ta are relatively consistent across the months, attributed to the site's proximity to the equator. As such, the PV system generation is expected to be fairly stable with minimal variations throughout the year.

Table 1. Solar resource of the selected locations [39]

\begin{tabular}{lc|lc}
\hline \multicolumn{1}{c}{ Location } & $\begin{array}{c}\text { Annual GHI }\left(\mathrm{kWh} / \mathrm{m}^{2}\right) / \\
\text { Relative percentage }(\%)\end{array}$ & \multicolumn{1}{c}{ Location } & $\begin{array}{c}\text { Annual GHI }\left(\mathrm{kWh} / \mathrm{m}^{2}\right) / \\
\text { Relative percentage }(\%)\end{array}$ \\
\hline United States - Sonoran Desert & $2,023.6 / 100.0$ & Laos - Vientiane & $1,824.2 / 90.1$ \\
Brunei - Bandar Seri & $1,817.1 / 89.8$ & Malaysia - Kuala Lumpur & $1,597.7 / 79.0$ \\
$\quad$ Begawan & $1,816.6 / 89.8$ & Myanmar - Naypyidaw & $1,848.8 / 91.4$ \\
Brunei - Tutong & $1,797.5 / 88.8$ & Philippines - Manila & $1,648.3 / 81.5$ \\
Brunei - Belait & $1,816.7 / 89.8$ & Singapore - Singapore & $1,629.8 / 80.5$ \\
Brunei - Bangar & $1,904.4 / 94.1$ & Thailand - Bangkok & $1,789.4 / 88.4$ \\
Cambodia - Phnom Penh & $1,666.9 / 82.4$ & Vietnam - Hanoi & $1,381.0 / 68.2$ \\
Indonesia - Jakarta & &
\end{tabular}

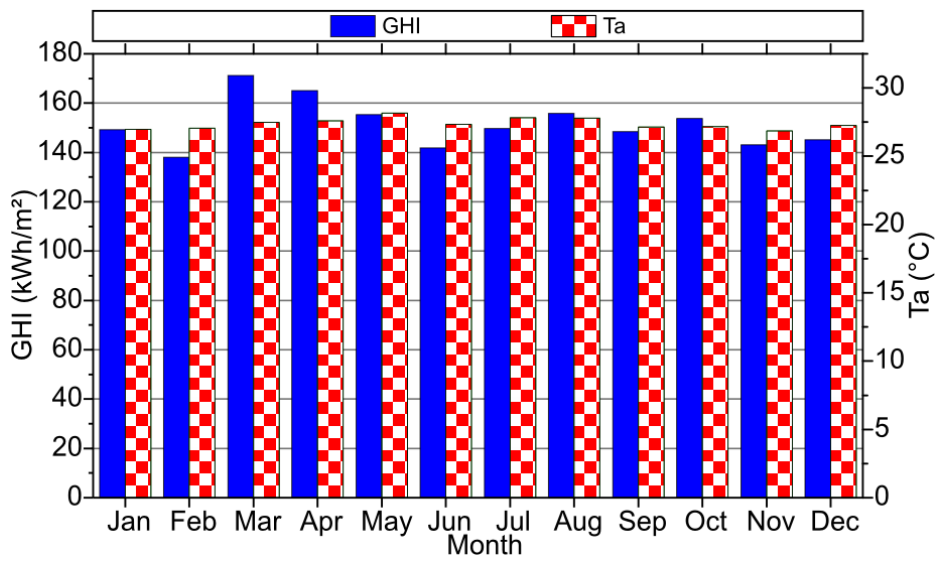

Figure 1. Monthly total GHI and mean Ta

\subsection{PV system}

PVsyst software package is used in designing the PV system incorporating the various variables as described in Subsection 2.2. Further, the hourly potential generation of the PV system under the meteorological condition of the installation site is computed in PVsyst for 8,760 hours over a year. PVsyst is an industrial-grade software package specializing in designing, sizing and analyzing a complete PV system [40]. It allows working with the meteorological data from various channels such as Meteonorm and customizing parameters to suit the requirements of each deployment. Here, the PV system model is developed based on the basic system configuration in [41]. The resulting generation dataset of the PV system from PVsyst will be utilized for performance evaluation and interconnection analysis.

The nominal PV system installation capacity is specified as $2 \mathrm{MWp}$. It represents a penetration ratio of $32 \%$ relative to the peak demand in the grid. The system comprises of 17,390 units of CdTe PV panel, arranged in 1,739 strings with ten series-connected panels. Table 2 displays the panel specification at the standard test conditions (STC) of $1,000 \mathrm{~W} / \mathrm{m}^{2}, 25^{\circ} \mathrm{C}$, and air mass of 1.5 .

Table 2. Specification of PV panel [42]

\begin{tabular}{lc|ll}
\hline Manufacturer & First Solar & Short-circuit current & $1.83 \mathrm{~A}$ \\
Model & FS-4115-3 & Open-circuit voltage & $87.6 \mathrm{~V}$ \\
Nominal power & $115.0 \mathrm{~W}$ & Current at maximum power & $1.66 \mathrm{~A}$ \\
Tolerance & $-0.0 \%,+4.3 \%$ & Voltage at maximum power & $69.3 \mathrm{~V}$ \\
\hline
\end{tabular}


In PVsyst, Shockley's simple one-diode model is used for describing the panel operation. In order to model the CdTe panel, recombination losses are introduced to the standard version of the one-diode model [43]. Figure 2 depicts the modified one-diode model utilized in this study. Correspondingly, the current at terminals of the panel $(I)$ is formulated in Equation (1). It is determined by photocurrent $\left(I_{p h}\right)$, diode current $\left(I_{\text {diode }}\right)$, recombination losses $\left(I_{\text {recomb }}\right)$, and current across resistance $\left(I_{r}\right) . I_{p h}$ is related to the solar irradiance and cell temperature where they are the key variables in dictating the output. Under any condition, the magnitude of $I_{p h}$ is with respect to the reference values of irradiance and temperature. Meanwhile, $I_{\text {diode }}$ is influenced by the PV cell temperature. $I_{\text {recomb }}$ reflects the leakage of current relating to $I_{p h}$ and voltage, as defined in Equation (2). The detailed formulation of other terms in Equation (1) can be found in [44]. Additionally, the parameters of exponential shunt resistance, voltage initial degradation, thermal parameters and quality of the panel are specified in PVsyst to suit the manufacturer's specification in [45].

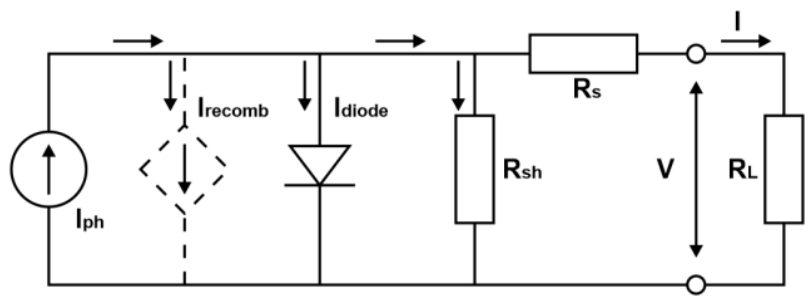

Figure 2. Modified one-diode model [43]

$$
\begin{aligned}
& I=I_{p h}-I_{\text {diode }}-I_{\text {recomb }}-I_{r} \\
& I_{\text {recomb }}=I_{p h} \times d i^{2} /\left[\mu \tau_{\text {eff }} \times\left[V_{b i}-\left(V+I R_{s}\right)\right]\right]
\end{aligned}
$$

where $d i$ : thickness of intrinsic i-layer, $\mu \tau_{e f f}$ : effective diffusion length of charge carriers, $V_{b i}$ : intrinsic voltage of junction, $V$ : panel voltage, $I$ : panel current and $R_{s}$ : series resistance.

In practice, the PV panel may be installed at any orientation for achieving the objective defined by the planner. It is related to the incidence angle $\left(\theta_{i}\right)$ between the panel and the sun, as given in Equation (3). Here, the objective is to maximize the annual solar radiation capturing of the PV panels for a maximum generation. The panels are designed as fixed orientation for lower system and operating expenditure. Since the site is situated in Northern hemisphere, the panels are oriented due South for gaining maximum sun exposure. It is recognized that the recommended minimum tilt angle for effective panel self-cleaning is $10^{\circ}$ [46]. Therefore, an exhaustive search for the optimal tilt angle was executed from $10^{\circ} \leq \beta \leq 90^{\circ}$ in the step of $\beta=0.1^{\circ}$. Resultantly, the optimal orientation is identified to be $\beta=10^{\circ}$ and $\gamma=0^{\circ}$, which is specified for the panels.

Since the panels are tilted, consideration is given to the reflection of solar radiation from the ground onto the panels. An albedo factor is used to quantify ground surface reflectivity, and it varies according to the surface material [47]. Here, it is specified as 0.20 for the installation on the surface covered with soil and grasses. Next, in accounting the effect of spectral irradiance deviation from STC on the panel performance, spectral correction factors are computed using Equation (4) [48]. The air mass and precipitable water content derived from Meteonorm are utilized as input parameters, along with coefficient sets of the panels. Resultantly, the monthly spectral correction factors are determined, ranging from a gain of $4.5 \%$ to $4.8 \%$.

Shading on the PV panels could bring about considerable system performance degradation. It is classified into (i) far shading due to surrounding obstructions such as tall building and (ii) near shading due to near objects such as adjacent PV panel. Far shading is disregarded in this study, given the inexistence of structure in the vicinity of the installation site. Near shading is accounted where it is corresponding to solar irradiance loss on PV cells. Here, the cell strips of the panels are set to portrait orientation for minimizing shading loss. The arrays are arranged recognizing the minimum inter-row panel spacing requirement $\left(D_{\text {min }}\right)$ for the solar productive period from 09:00 hour to 15:00 hour determined using Equation (5).

$$
\begin{aligned}
\cos \theta_{i}= & \sin \delta \sin \varphi \cos \beta-\sin \delta \cos \varphi \sin \beta \cos \gamma+\cos \delta \cos \varphi \cos \beta \cos \omega+ \\
& \cos \delta \sin \varphi \sin \beta \cos \gamma \cos \omega+\cos \delta \sin \beta \sin \gamma \sin \omega
\end{aligned}
$$

where $\delta$ : solar declination angle, $\varphi$ : latitude, $\beta$ : tilt angle, $\gamma:$ azimuth angle, $\omega$ : solar hour angle. 


$$
M=b_{o}+b_{1} \cdot A M_{a}+b_{2} \cdot p_{w a t}+b_{3} \cdot \sqrt{A M_{a}}+b_{4} \cdot \sqrt{p_{w a t}}+b_{5} \cdot A M_{a} / \sqrt{p_{w a t}}
$$

where $M$ : spectral correction factor, $b_{o}: 0.86273, b_{1}:-0.038948, b_{2}:-0.0125060, b_{3}: 0.098871, b_{4}$ : $0.084658, b_{5}:-0.0042948, A M_{a}:$ absolute air mass and $p_{w a t}:$ precipitable water.

$$
D_{\min }=(\sin (\beta) \times W / \tan H) \times \cos \theta_{a z}
$$
shading hours.

where $W$ : panel width, $H$ : sun height angle of no shading hours and $\theta_{a z}$ : azimuth angle of no

The solar inverter is incorporated in the PV system for DC power conversion to AC power usable in the grid. In this study, inverter selection is focused on SMA products, noting its industry-leading product specification and global installation track record, in addition to business presence in neighboring countries. In view of the PV system installation capacity, only string-type and centralized-type inverters are considered. A comparison is made among three inverter models currently available in the market (String-type: Sunny Tripower 60; Centralized-type: Sunny Central 500, Sunny Central 1000) in terms of their operating performances in relation to time-varying generation of the PV panels. Sunny Central 1000 is selected as it is deemed to incur least energy loss. Table 3 presents the specification of Sunny Central 1000. Given the nominal capacity, two units of the inverter are required for the PV system. It is worth emphasizing that Sunny Central 1000 may operate with a power factor (PF) at unity or from -0.9 to +0.9 , depending on the preference of grid operator. Here, the inverters' PF are set to 0.95 overexcitation mode for active and reactive power export.

Table 3. Specification of the inverter [49]

\begin{tabular}{lc|lc}
\hline Model & SMA Sunny Central 1000 & MPP voltage range at & $688-850 \mathrm{~V}$ \\
& & $25^{\circ} \mathrm{C}$ & \\
Maximum DC power $(\mathrm{PF}=1.0)$ & $1,122 \mathrm{~kW}$ & AC power at $25^{\circ} \mathrm{C}$ & $1,100 \mathrm{kVA}$ \\
Maximum input voltage & $1,000 \mathrm{~V}$ & Nominal AC voltage & $405 \mathrm{~V}$ \\
\hline
\end{tabular}

To assess the performance of the PV system, three standardized performance indices in conformity with IEC EN 61724 viz. final yield $(Y f)$, reference yield $(Y r)$ and performance ratio $(P R)$ are computed [50]. In the solar PV industry, these indices are utilized in conducting a direct comparison between the PV systems of different designs, orientations, and installation locations. The first index, $Y f$ is the final system generation $\left(E_{\text {out,final }}\right)$ relative to the rated capacity of the PV arrays at STC $\left(P_{\text {array }}\right)$, as defined by the mathematical expression in Equation (6). The resulting value is expressed either in $\mathrm{kWh} / \mathrm{kWp}$ or hour. It also reflects the duration the arrays are needed to operate at the rated output for obtaining the equivalent final generation. Meanwhile, $\mathrm{Yr}$ evaluates solar resource availability for the PV system. It is computed as total in-plane solar irradiance $\left(G_{\text {actual }}\right)$ divided by reference in-plane solar irradiance $\left(G_{\text {ref }}\right)$, as formulated in Equation (7). Theoretically, for the arrays operating at $\mathrm{STC}, 1 \mathrm{kWh} / \mathrm{m}^{2}$ of solar irradiance results in the generation of 1 $\mathrm{kWh} / \mathrm{kWp}$. The third index, $P R$ is the overall system efficiency corresponding to nominal installed power and incident energy. It is defined in Equation (8) as the final yield $(Y f)$ with respect to the reference yield $(Y r)$.

$$
\begin{aligned}
& Y f=E_{\text {out }, \text { final }} / P_{\text {array }} \\
& Y r=G_{\text {actual }} / G_{r e f} \\
& P R=Y f / Y r
\end{aligned}
$$

\subsection{Microgrid}

The grid envisaged for the PV system integration in the present study is based on an isolated $11 \mathrm{kV}$ 10-bus microgrid in Brunei. Figure 3 displays the simplified single line diagram of the grid. 


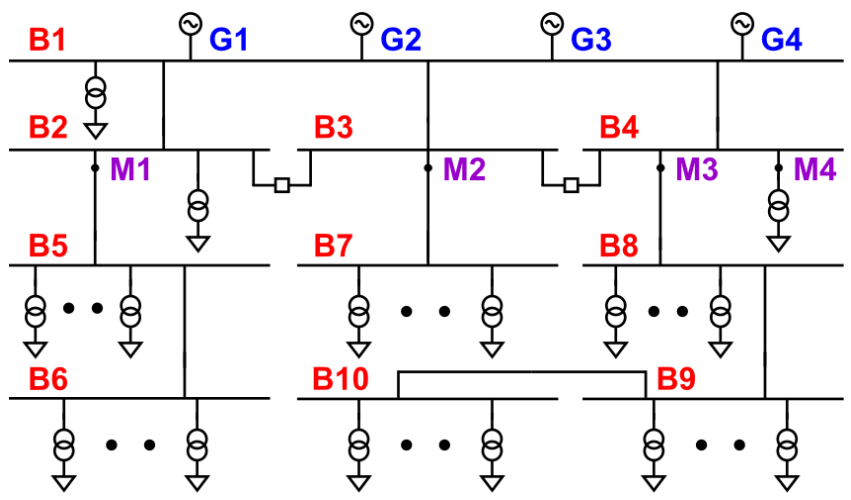

Figure 3. Simplified single line diagram of the grid

The grid is rated at $11 \mathrm{kV}$ line-to-line voltage with diesel generator sets (gensets) as the sole generation source. They are 10-pole, $50 \mathrm{~Hz}$ salient-pole synchronous machines represented by G1 to G4 in Figure 3. G1 and G2 have the same rated capacity of 3.886 MVA whereas G3 and G4 are 3.754 MVA. Under the normal operating conditions, three gensets are put in operation with the remaining on standby. The generation is proportional among the gensets with the application of genset paralleling capability. Presently, power flow in the grid is unidirectional, where the power is generated at the main generation station and transferred to downstream loads. B1 is a generation bus, and it is specified as the slack bus. B2 to B4 are bus sections of the network switchboard in supply substation. Meanwhile, B5 to B10 are load buses. The existing grid protection scheme is constituted of the overcurrent protection system. It is modeled by utilizing the combinations of overcurrent relay, current transformer and circuit breaker, resembling the actual configuration in the grid.

Nine representative load profiles derived from long-term demand measurements, which are observed by the utility for grid planning are considered. Figure 4 illustrates the hourly demand measurements for M1 to M4 from 06:00 hour to 17:00 hour corresponding to each load profile normalized to the maximum value. It can be noted that the demand variation is substantial across the load profiles. Load profiles A to D represent the high demand period, whereas load profiles E to I reflect the low demand period. The demand is usually higher in the afternoon, mainly due to increased usage of the cooling system.

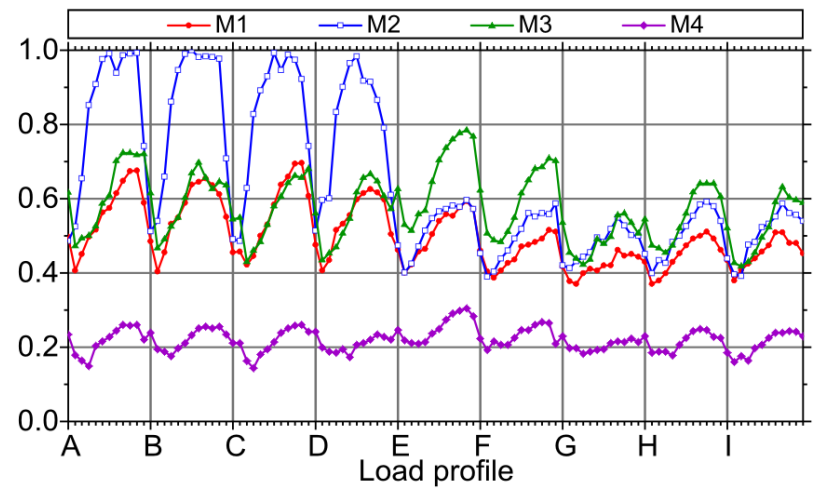

Figure 4. Normalized hourly electricity demands

\subsection{Interconnection of the PV system}

ETAP software package is employed for modeling and analyzing the grid in hybrid operation with the PV system. ETAP is a well-recognized power system software package specializing in grid modeling, analysis, and operation [51]. It is capable of executing a myriad of grid analytical studies within a single platform, including power flow assessment, short-circuit analysis, dynamic transient stability analysis, and real-time monitoring and simulation. Besides, it consists of an extensive component database and allows component customization according to the user-defined parameter for matching the exact manufacturer's specification. The PV system is designed as an active and reactive power (P-Q) controlled source in ETAP, based on the model in PVsyst. Noting the geographical limitation, the potential points for the PV system interconnection are at B5, B7, and B8. Table 4 summarizes the scenarios of the interconnection considered in this study. 


\begin{tabular}{lcccc}
\multicolumn{5}{c}{ Table 4. Description of interconnection scenario } \\
\hline Scenario & 1 & 2 & 3 & 4 \\
Interconnection point & Base case (existing grid) & B5 & B7 & B8 \\
\hline
\end{tabular}

\subsection{PV system interconnection assessments}

In the present study, the power flow algorithm utilizing the Newton-Raphson method is adopted for computing the grid operating variables. It involves an iterative computation process based upon the fundamental active and reactive power flow equations defined in Equations (9) and (10).

$$
\begin{aligned}
& P_{i}=\sum_{k=1}^{n}\left|V_{i}\right|\left|V_{k}\right|\left(G_{i k} \cos \theta_{i k}+B_{i k} \sin \theta_{i k}\right) \\
& Q_{i}=\sum_{k=1}^{n}\left|V_{i}\right|\left|V_{k}\right|\left(G_{i k} \sin \theta_{i k}-B_{i k} \cos \theta_{i k}\right)
\end{aligned}
$$

where $V_{i}$ : voltage at bus $i, V_{k}$ : voltage at bus $k, G_{i k}$ : real part of admittance matrix element, $B_{i k}$ : imaginary part of admittance matrix element and $\theta_{i k}$ : phase angle.

As mentioned, the inherent operating characteristic of the PV system may create a mismatch between generation and demand and potentially lead to jeopardizing the normal grid operation. The most critical challenge to the grid operation is presented during the maximum PV system generation. The steadystate grid operations from 06:00 hour to 17:00 hour for each interconnection scenario are assessed corresponding to the time-varying load profiles and the maximum PV system generation profile derived from the PVsyst simulation. A total of 432 hourly conditions are examined in the time-series power flow assessment. The assessment is focused on the generation, loading and PF of the gensets, along with the grid operating parameters including power flow, bus voltage and line loading at the respective point-of-commoncoupling (PCC), and line losses.

It is worth mentioning that the existing grid protection scheme is designed relevant to the operation without the PV system in the grid. Therefore, with the presence of the PV system, the grid protection system is risked to technical challenges such as overloading of the protection device, relay misoperation, and loss of proper coordination between the relays. Short-circuit analysis in accordance to IEC 60909 standards is carried out in ETAP. The cases of a fault occurring at each bus for all the interconnection scenarios are examined. The objectives are to assess the adequacy of existing protection devices and the validity of the protection scheme.

Besides the intermittent and non-dispatchable characteristics of the PV system, the integration may challenge the grid in terms of the available inertia and spinning reserve. Unlike the genset, the PV system incorporating electronic-based solar inverter contributes no inertial response to grid energy balance. Consequently, the grid may be risked to instability following a disturbance. It shall be pointed out that the grid is not implemented with the under-frequency load shedding scheme. The following three cases representing the most critical operating conditions are identified for assessment.

a) Case 1: Peak PV system generation at high demand period

b) Case 2: Peak PV system generation at low demand period

c) Case 3: Maximum demand at low demand period with respective PV system generation

For each case of the critical operating conditions, the dynamic transient stability analysis is performed in ETAP corresponding to the following potential extreme grid disturbance events to analyze the resulting frequency and voltage responses at the main generation station for determining the grid stability.

a) Sudden tripping of the PV system

b) Rapid PV system generation ramp-down at various rates

c) PV system generation fluctuation

d) Sudden loss of generation from the genset

For continuous and stable operation, the frequency and voltage shall lie within the range of $\pm 5 \%$ of their nominal values. Otherwise, the grid shall deem to lose its stability and lead to grid collapse.

A multi-objective optimization based on time-series power flow algorithm is executed to ascertain the optimal placement of the PV system in the grid. All the potential interconnection points are nominated, subjected to no violation of voltage and line ampere loading limit reported from the power flow assessment. Further, any nominated point encountered with the limit violation in the computation process will be disqualified. The objectives of the optimization are to elevate the technical merits of the grid operation through line loss reduction, voltage profile enhancement, and line reserve capacity improvement. It is undertaken as a multi-objective optimization problem, accounting three technical performance indices active line losses index $(A L L I)$ and voltage index $(V I)$ based on the formulation in [41], and line capacity index $(L C I)$. 
The first index, ALLI is defined in Equation (11). It measures the total active line losses in the PVintegrated grid relative to that of without the PV system using average generation and demand profile. By it, the resulting value closer to zero is desirable as it indicates lower losses and a higher utilization efficiency per unit of electricity generated.

$$
A L L I=\sum_{h=1}^{n h} P_{l o s s, h}^{n e w} / \sum_{h=1}^{n h} P_{l o s s, h}^{\text {base }}
$$

where $P_{\text {loss }, h}^{\text {new }}$ : cumulative active line losses in the grid with PV system during hour $h, P_{\text {loss }, h}^{\text {base }}$ : cumulative active line losses in existing grid without PV system during hour $h$ and $n h$ : total number of hours.

The second index, $V I$ is an indicator of the grid voltage deviation from the nominal value with respect to the average generation and demand profile. It is expressed by the mathematical formula in Equation (12). Higher adherence to the nominal voltage is reflected by a smaller VI. It implies a lower limit violation risk. In the computation, all the buses are accounted except the slack bus as its voltage magnitude is pre-specified.

$$
V I=\sum_{h=1}^{n h}\left|\left(V_{n o m}-V_{b, h}\right) / V_{n o m}\right|_{b=2}^{n b} /(n h \times n b)
$$

where $V_{\text {nom }}$ : nominal voltage magnitude, $V_{b, h}$ : voltage magnitude of bus $b$ at hour $h$ and $n b$ : total number of buses.

The third index, LCI is formulated in Equation (13). It defines the maximum ratio of the current flow through the line over the line ampacity corresponding to the time-varying demand and the respective peak and minimum PV system generation. A lower magnitude of LCI indicates a higher reserve capacity of the line, which is beneficial for future load growth.

$$
L C I=\max \left[\left(\left|I_{l, h}^{p v g}\right|_{p v g=\min }^{p v g=\text { eak }} / M C C_{l}\right)_{l=1}^{n l}\right]_{h=1}^{n h}
$$

where $I_{l, h}^{p v g}$ : current flow through line $l$ at the respective PV system generation level $p v g$ during hour $h, M C C_{l}$ : ampacity of line $l$ and $n l$ : total number of lines.

A weighting factor is allocated to each index based on the significance of their contribution to the optimization solution. Here, factors of $0.5,0.3$ and 0.2 are specified for $A L L I, V I$ and $L C I$, respectively. They may be modified accordingly to suit a given objective, subjected to the summation equates to 1.0.

Given in Equation (14), the multi-objective performance index $(M O P I)$ is computed from the summation of the weighted performance indices. The objective function of the optimization is to minimize MOPI, as defined in Equation (15). As such, the optimal PV system placement in the grid is being the nominated point resulting in the minimal $M O P I$, reflecting the highest potential in enhancing the grid operation.

$$
\begin{aligned}
& M O P I=\alpha_{1} A L L I+\alpha_{2} V I+\alpha_{3} L C I \\
& f=\text { minimize }(M O P I)
\end{aligned}
$$

where $\alpha_{1}$ : weighting factor of $A L L I, \alpha_{2}$ : weighting factor of $V I$ and $\alpha_{3}$ : weighting factor of $L C I$.

\section{RESULTS AND DISCUSSION}

\subsection{PV system performance}

In order to estimate the annual generation of the PV system, the potential generation for 8,760 hours over a year is computed in PVsyst accounting the meteorological condition and design variables described in Section 2. Cumulatively, the system is expected to yield annual energy of 3,293 MWh. According to [52], this amount of energy could realize a yearly saving of 5,598 barrels of fuel, coupled with carbon emission reduction up to 2,960 tons. From the financial perspective, a massive benefit could be accumulated from lessened fuel cost and carbon tax over the system operational lifetime.

Figure 5 shows the variation of total generation in each month of the year. The PV system generation is governed mainly by irradiance and Ta. The generation is highest in March at $312 \mathrm{MWh}$ as it is the month receiving the highest total irradiance. On the other hand, the minimum monthly generation is in June at $242 \mathrm{MWh}$. Though a higher monthly irradiance is available in June than February, its higher Ta attributed to a lower energy conversion efficiency. In Figure 6, the normalized maximum and average generation profiles are illustrated. The PV system generation is corresponding to the hour from 06:00 to

Towards energy transition: conjoint assessment of large-scale PV system performance ...(Zen L. Chai et al) 
17:00. The hourly magnitude of average generation profile equates the total generation for the specific hour divided by number of data available. With regard to maximum generation profile, the generation at 06:00 hour is $1.31 \%$ that of at 12:00 hour. It indicates a large difference in the amount of PV system energy injection into the grid across the hours.

Based on the meteorological and generation data, the $Y f, Y r$ and $P R$ are computed to evaluate the performance of the PV system. It is determined that the PV system operating under the tropical climatic condition achieves $Y f$ of $4.51 \mathrm{kWh} / \mathrm{kWp} /$ day, which is lower than the installation at Morocco with arid climate $(1,895 \mathrm{kWh} / \mathrm{kWp} /$ year $)$ [53]. Additionally, comparison with performance monitoring data of other installations found that it is higher than Brazil (3.4 kWh/kWp/day) [54] and Mauritania (4.27 kWh/kWp/day) [55], matches with Kuwait (4.5 $\mathrm{kWh} / \mathrm{kWp} /$ day) [56], and lower than India (4.81 kWh/kWp/day) [57]. Meanwhile, the $Y r$ is estimated to be 4.98 hours, denoting the number of peak sun hours per day. Besides the meteorological condition and installation location, it is influenced by the panel orientation. It also indicates that the system generation at STC is equivalent to $4.98 \mathrm{kWh} / \mathrm{kWp} /$ day. Figure 7 presents a comparison of the monthly $P R$. Overall, the highest system efficiency reaches the $P R$ of $90.94 \%$ in February whereas the lowest is $90.29 \%$ in May. It is dictated by losses in the energy generation process, for instance, due to shading, panel temperature, and inverter efficiency. The high potential of deploying the PV system is justified by the promising monthly $P R$ with a strong yearly $P R$ of $90.6 \%$ which is greater than the installation in Brazil (68\%) [54], Mauritania (67.96\%) [55] and Morocco (82.2\%) [53], and close to that of in India (89.15\%) [57].

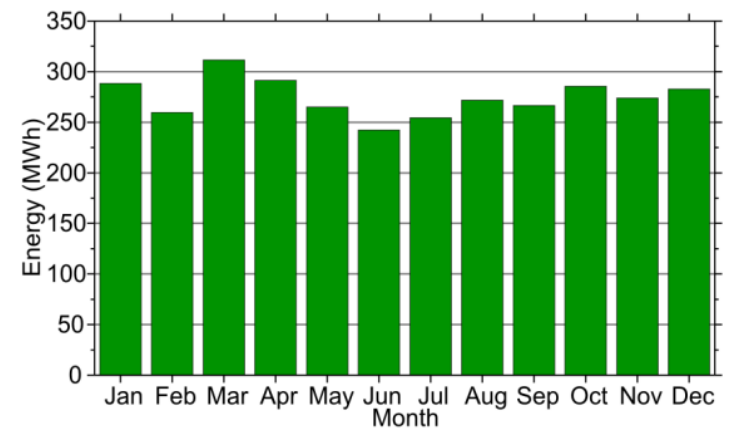

Figure 5. Monthly PV system generation

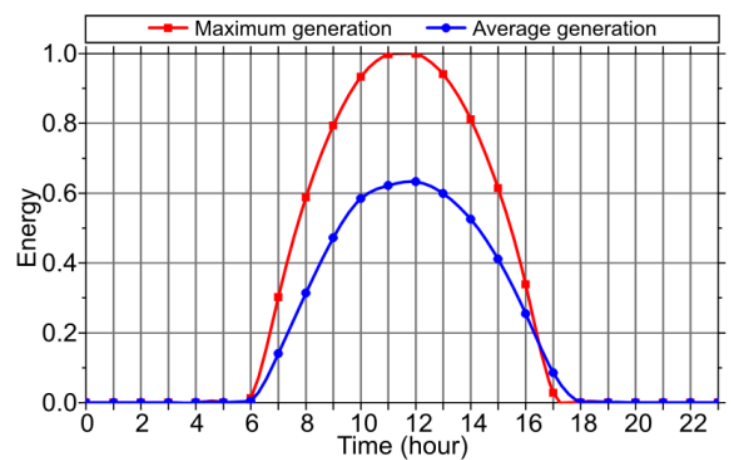

Figure 6. Normalized maximum and average generation profiles

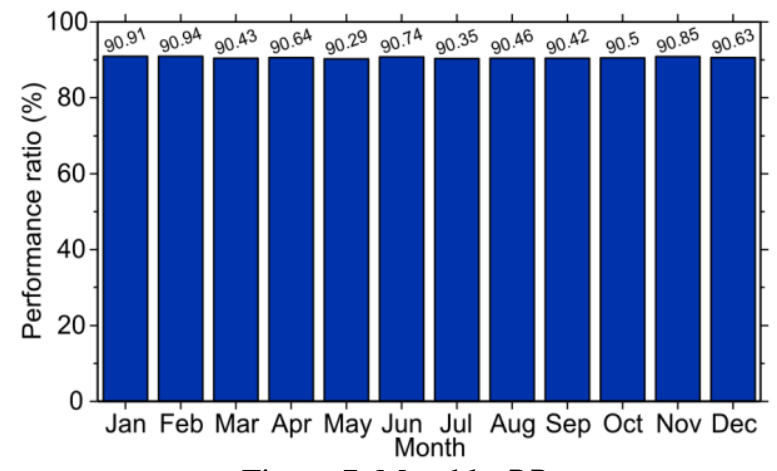

Figure 7. Monthly $P R$ 


\subsection{Time-series power flow assessment}

\subsubsection{Synergy between the PV system and genset}

The interconnection impacts are examined from the perspective of genset operation, focusing on the generation, loading level, and PF. Figure 8 illustrates the total active and reactive energy generations of the gensets in the existing grid versus those of the grid with the PV system corresponding to each load profile. From the comparison, it is obvious that the synergy brings about a reduction in the genset generation. The maximum reductions of the active and reactive energy generations are attained in load profile $\mathrm{G}$ up to $29.1 \%$ and $33.8 \%$, respectively. The finding shows the benefit of operating the inverters at PF of 0.95 overexcitation, whereby the genset generation burden is relieved in terms of both active and reactive elements. It signifies the grid operator may leverage the PF range offered by the inverters in providing necessary grid support.

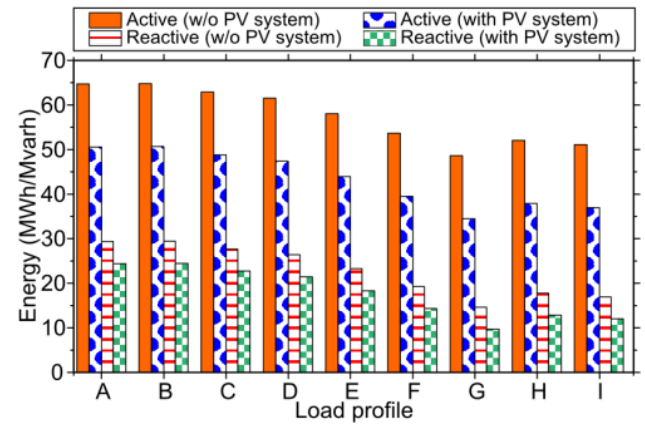

Figure 8. Active and reactive energy generations of the gensets

The loading of the genset is defined as the energy generation relative to the rating. In Figure 9, the impact on the hourly genset loading corresponding to the load profile is depicted. The comparison shows the resulting lower loadings in all the hours. For instance, the peak hourly loading at 16:00 hour in load profile A is reduced up to $7.1 \%$. It suggests an opportunity of delaying the necessity of expanding the conventional generation capacity of the grid in view of the growing demand, which agrees with the finding reported by Barsoum and Lee in [35]. The present study goes beyond the previous work, pointing out the event of the genset loading lower than $30 \%$ during the low demand period (load profiles E to I). This violates minimum genset loading requirement and subsequently, triggers dispatch issue. During those hours, proper genset sequencing by curtailing the number of operating genset to suit is necessary. It is done, however, at the expense of reduced system inertia and spinning reserve available in the grid. Hence, evaluation of the impact on the grid stability will be performed in this study through the dynamic transient stability analysis.

The inverter PF defines the proportion of active and reactive power injections from the PV system into the grid, which in turn influences the genset PF. Given the wide operating PF range of the inverters, an assessment is carried out to analyze the corresponding impact on the operating PF of the gensets. Figure 10 displays the hourly genset PF at different inverter PF for each load profile. Generally, the stable genset operation is restricted to within 0.80 lagging to unity PF, in accordance with the capability curve. As shown in Figure 10, the genset PF well conforms to the acceptable range while operating the inverters at PF of 0.95 overexcitation, which is specified for the PV system. Contrarily, setting the inverter PF either to 0.90 overexcitation or unity risks limit violation due to the resulting generation imbalance of the genset. The finding concerning the PV system poses an effect on the genset PF is in line with the work accounting only unity PF by Farhoodnea et al. in [58]. Therefore, proper reactive power management in the grid is crucial, whereby the permissible inverter PF must be specified for the interconnection.

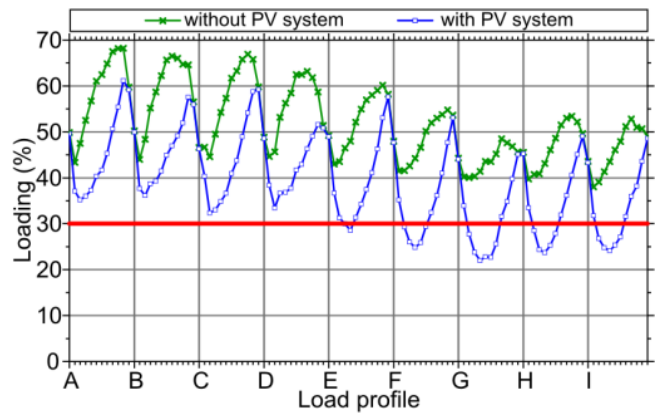

Figure 9. Loadings of the gensets 


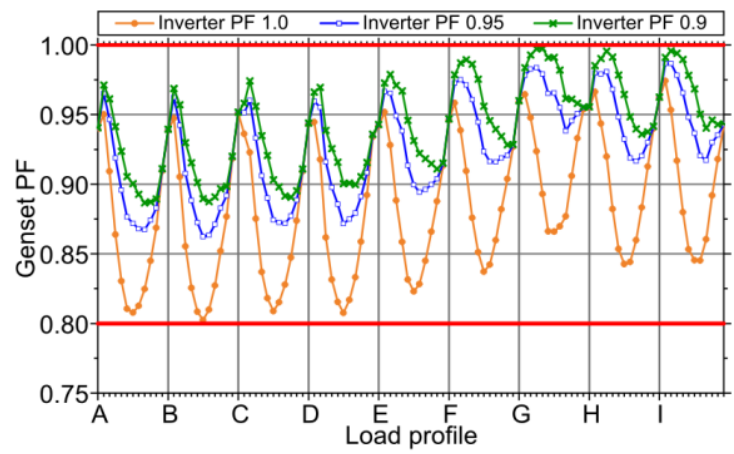

Figure 10. Operating PF of the gensets

\subsubsection{Grid operating parameters}

The impact of the PV system integration on the power flow at PCC is assessed. Figure 11 illustrates the time-series active power flow through the line for each interconnection scenario normalized to the maximum value. It is noteworthy the existence of negative power flow, indicating the power is in the opposing direction from the convention. This occurs due to the mismatch between generation and demand, leading to the PV system energy oversupply exceeding the downstream demand. The situation is presented in all the load profiles of Scenarios 2 and 4 whereas only during the low demand period in Scenario 3. In such a case, the power flow in the grid is transformed into bidirectional. Since the grid is designed for unidirectional power flow, the normal grid operation may potentially be challenged. Therefore, the impacts on the grid operating parameters in terms of bus voltage, line ampere loading and losses shall be examined.

Figure 12 displays the voltage profile at the PCC for each interconnection scenario with respect to the load profile. Scenario 2 presents the most significant hourly voltage variation per load profile, and it is also the most susceptible to limit violation. In Scenario 3, a higher voltage profile is exhibited in load profiles E to I due to the substantial lower electricity demand. Meanwhile, the voltages in Scenario 4 show a relative consistency across all the load profiles. In accordance with the national grid code, the allowable voltage range for safe and reliable operation is specified to be \pm 0.05 per unit quantities (p.u.) of the nominal voltage. Dissimilar to the finding in [30] corresponding to a typical grid, no voltage limit violation is reported, albeit the presence of reverse power flow. Moreover, the resulting voltages are far from violating the limits. For instance, at the PV system generation amounting to $179.6 \%$ of the downstream demand in Scenario 2, the corresponding voltage is 1.006 p.u. - a voltage rise of $1.13 \%$ only. The finding implies a higher magnitude of reverse power flow could be sustained at the PCC while adhering to the limits.

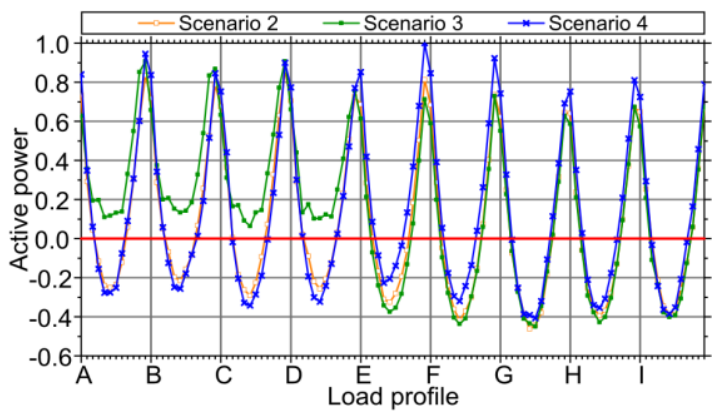

Figure 11. Normalized active power flow at PCC

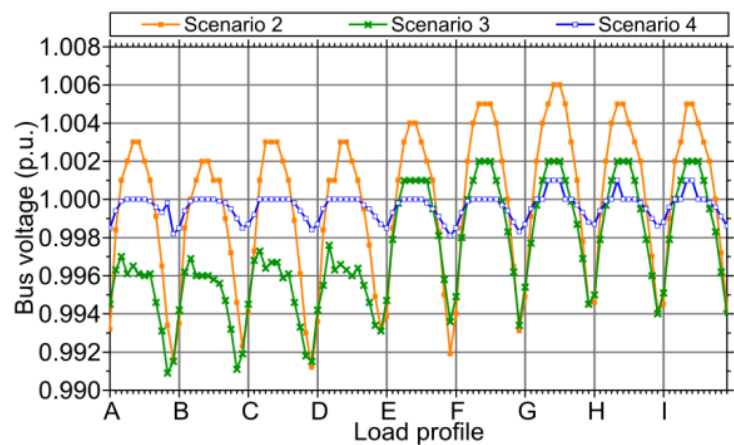

Figure 12. Operating voltages at PCC 
The power transfer in the grid involves voltage drop, leading to a lower voltage at the distribution end. A global concern to the grid operators is the possible undervoltage issue in the grid at times of high demand. Figure 13 presents the impacts of the PV system on the maximum and minimum PCC voltages for each interconnection scenario. It is apparent that both maximum and minimum voltages rise with the PV system deployment. The voltage rise is attributed to the proximity of the PV system to the loads. The comparison between the scenarios suggests the opportunity in leveraging the interconnection point for managing bus voltages. It could, in turn, maximize loadability for catering more future loads without risking limit violation.

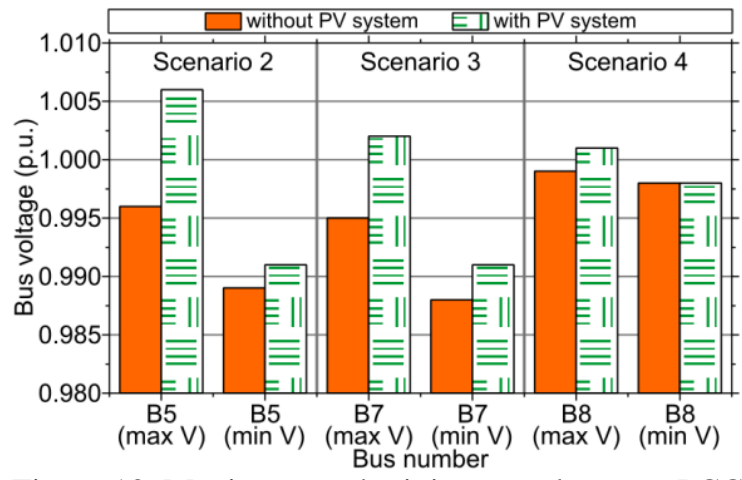

Figure 13. Maximum and minimum voltages at PCC

Line ampere loading is defined as the percentage of the current flowing through the line over the rated ampacity. The rated ampacity of the line at PCC of all the interconnection scenarios are 470A, and the maximum line ampere loading limit is specified as 75\%. Figure 14 illustrates the comparison of the maximum and minimum line ampere loadings at PCC before and after the PV system interconnection in each scenario. Despite having the reverse power flow, both maximum and minimum loadings are reduced with the PV system in the grid. The maximum loadings in all the scenarios with the PV system are well below $25 \%$. As such, there is no overloading risk, and no replacement of the existing line is necessitated for accommodating the PV system. The finding is consistent with the work by Wu et al. [26] on Taiwanese grids that the PV system makes available a larger line reserve capacity, thus allowing deferment of line reinforcement. It is worth highlighting that the present study considered time-varying nature of generation and demand in determining the loadings.

In Figure 15, the total line losses resulting in each interconnection scenario corresponding to the load profile are displayed. From the comparison, the potential of the PV system in reducing the losses is shown. It is mainly attributed to the lower power transfer in the lines. The reductions signify an improvement in the grid operating efficiency. Further, the comparison between the scenarios within a load profile demonstrates the relationship of the line losses with the interconnection point. It indicates an opportunity for the grid planner in specifying the optimal point for the interconnection to maximize grid operation enhancement. It is noteworthy that the loss minimization potentials of the scenarios are distinctive across different load profiles. For instance, the least total line losses in load profile A is achieved in Scenario 3 whereas that of in load profile $\mathrm{E}$ is in Scenario 2. This reveals the significance of considering long-term feeder-specific load profiles in identifying the optimal PV system placement in the grid to achieve minimal losses.

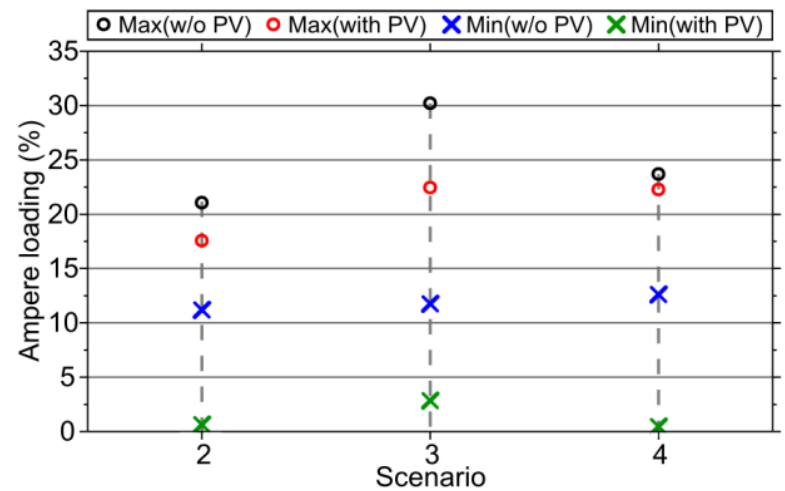

Figure 14. Maximum and minimum line ampere loadings 


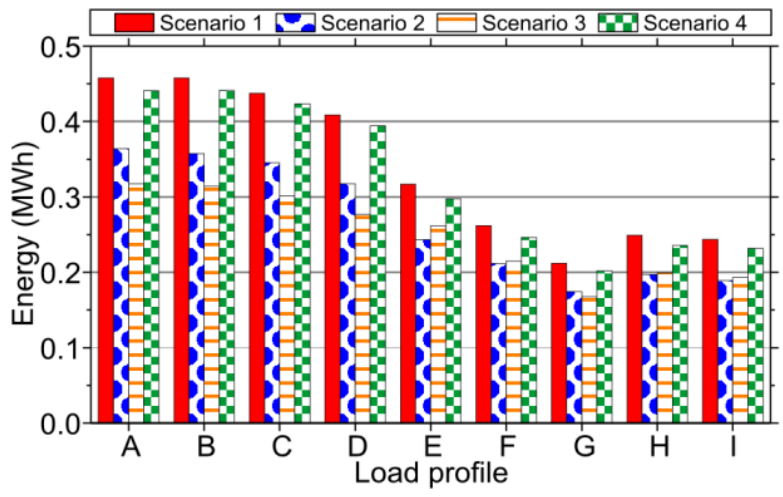

Figure 15. Total line losses

\subsection{Short-circuit analysis}

Based on IEC 60909 standards, the occurrence of a balanced three-phase fault is simulated at each bus (except the slack bus) for assessing the fault current. Table 5 summarizes the maximum fault current level in the grid corresponding to each interconnection scenario. The comparison indicates the maximum fault current level increases with the presence of the PV system, up to $0.56 \%$ in comparison with Scenario 1. Despite that, the short-circuit ratings of all the existing breakers of $25 \mathrm{kA}$ are not violated. Hence, breaker replacement is not necessitated as their operating capabilities are not compromised.

Table 5. Maximum fault current level

\begin{tabular}{lcccc}
\hline Scenario & 1 & 2 & 3 & 4 \\
\hline Fault current (kA) & 4.674 & 4.700 & 4.699 & 4.698 \\
\hline
\end{tabular}

The operation of the protection device for the fault occurring at the bus downstream of the PVintegrated bus is analyzed. In Table 6, impacts on the fault current level and relay operating time with respect to each interconnection scenario are presented. It is determined that the fault current increases by $0.97 \%$ in Scenario 2 and $0.24 \%$ in Scenario 4 . Subsequently, the protection device operation is affected by faster relay operating time, which agrees with the work in [36]. Given the minimal variations of two milliseconds in both scenarios, the relay coordination scheme remains within acceptable time grading margin.

Additionally, the event of the fault happening at the bus adjacent to the PV-integrated bus is examined. Table 7 provides the magnitude of fault current flowing in reverse through the upstream protection devices in each scenario. In all the scenarios, the reverse fault current does not trigger relay misoperation as the pickup current of the upstream protection device is not met. Nevertheless, the finding suggests the application of the protection device with the directional element in the case of having a larger PV shortcircuit capacity. Based on the findings, the existing protection scheme is deemed to remain valid in view of the interconnection.

Table 6. Downstream fault current and relay operating time

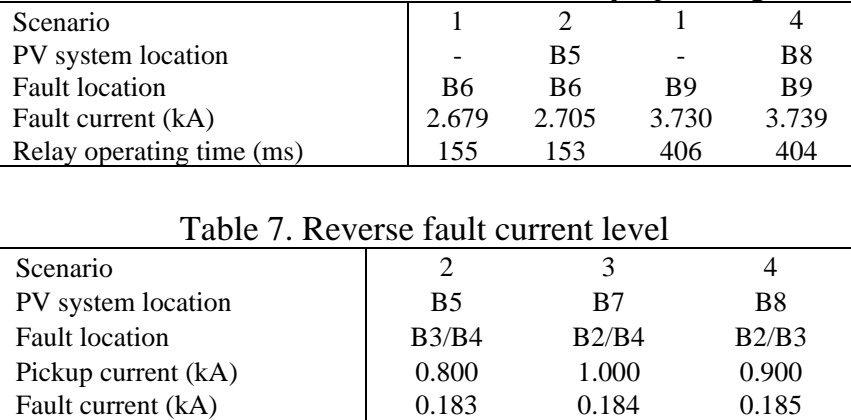

\subsection{Dynamic transient stability analysis}

The grid stabilities for the extreme disturbance events corresponding to different cases of critical operating conditions as described in the following are assessed, in terms of the system frequency and voltage at the main generation station. Case 1 represents the grid operating condition during the high demand period at which the demand is the highest at the peak PV system generation. In this case, three gensets are in operation. Meanwhile, Cases 2 and 3 consider the low demand period when only two gensets are operating in 
accordance with the minimum genset loading threshold. As such, the available dynamic support in the grid is limited. Case 2 focuses on the condition of the highest demand at peak PV system generation. For Case 3, it is corresponding to the maximum demand condition of the period with the respective PV system generation.

\subsubsection{Event 1: Sudden tripping of the PV system}

The sudden opening of the PV system breakers at 2 seconds, entailing the entire loss of PV system energy injection in the grid is simulated. This event may arise from circumstances such as grid disturbance and unintended breaker operation. It poses a remarkable challenge to the normal operation of the gensets. Figure 16 depicts the resulting system frequency and voltage of Case 1. Both system frequency and voltage remain within the acceptable range. The drops are attributed to the abrupt energy imbalance in the grid. Similar response patterns are presented in Cases 2 and 3 without limit violation. The minimum frequencies recorded in Cases 1, 2 and 3 are 98.2\%, 97.3\% and 97.8\%, respectively. Meanwhile, the minimum voltages for Cases 1, 2 and 3 are 0.984 p.u., 0.972 p.u. and 0.976 p.u., respectively. The analysis indicates that the grid is capable of sustaining its stability for the event. This implies the rapid inertial response of the gensets and spinning reserve allocation in the grid are adequate for compensating the sudden supply loss from the PV system.
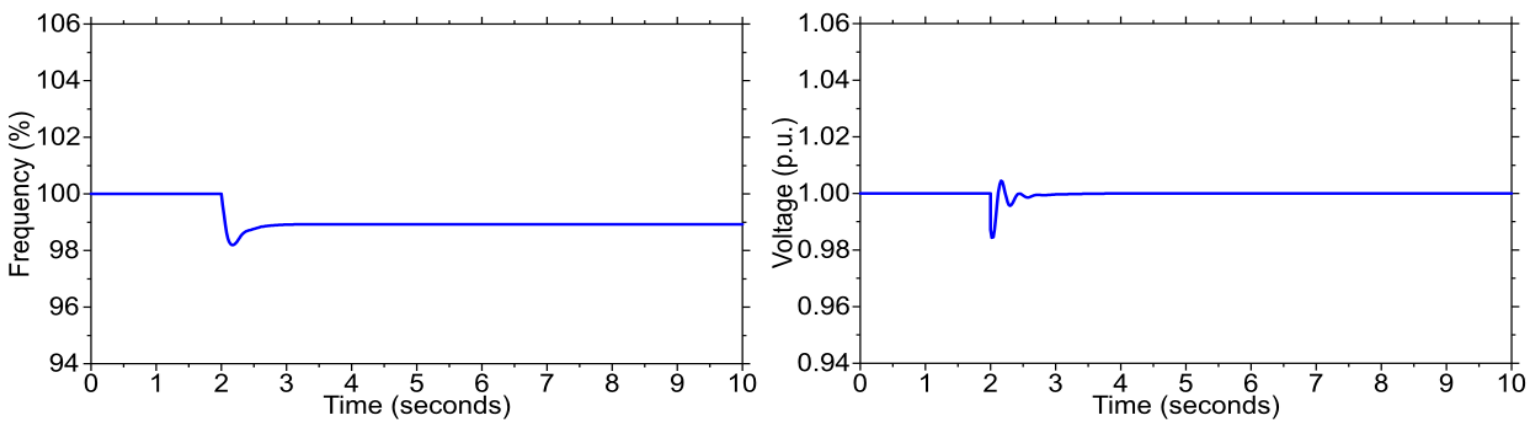

Figure 16. System frequency (left) and voltage (right) responses of Case 1 during Event 1

\subsubsection{Event 2: Rapid PV system generation ramp-down at various rates}

The impact of PV system generation ramps down by $85 \%$ in 0.5 minutes, 1 minute and 2 minutes are investigated. It mimics the passage of clouds during extreme weather conditions with subsequent shadowing of the PV arrays. Table 8 presents the comparison of the minimum system frequency obtained in each case corresponding to different ramp-down intervals. The event prompts an increment of the generation of the gensets. Despite the lessened inertia available in Cases 2 and 3, the system frequencies in all the cases are dropped within the limit. Further, the results indicate an inverse relationship between minimum frequency and ramp-down rate. It points out that the highest ramp-down rate shall be accounted during grid planning as it shall pose a higher risk of limit violation. Meanwhile, the system voltages swing within the bound during the event and return to stability thereafter. For instance, the minimum voltages for Cases 1, 2 and 3 for ramping down in 0.5 minutes are 0.9999 p.u., 0.9998 p.u. and 0.9999 p.u., respectively. The resulting system frequency and voltage demonstrate the preservation of grid stability, without requiring the PV system energy injection reduction proposed in [38] for Kiribati's grid during low demand at maximum PV system generation.

Table 8. Minimum system frequency at PV system generation ramp-down

\begin{tabular}{|c|c|c|c|}
\hline Case Interval & $0.5 \mathrm{~min}$ & $1 \mathrm{~min}$ & $2 \min$ \\
\hline 1 & $99.083 \%$ & $99.084 \%$ & $99.243 \%$ \\
\hline 2 & $98.629 \%$ & $98.631 \%$ & $98.632 \%$ \\
\hline 3 & $98.870 \%$ & $98.872 \%$ & $98.873 \%$ \\
\hline
\end{tabular}

\subsubsection{Event 3: PV system generation fluctuation}

A randomized fluctuation of the PV system generation within the range of $5 \%$ to $100 \%$ for 2.5 minutes is simulated. This event imitates the variable cloud movement and considers the intermittent nature of the PV system generation. Figure 17 illustrates the corresponding system frequency and voltage responses for Case 2. Similar characteristics of system responses are yielded in Cases 1 and 3. The minimum frequencies recorded in Cases 1, 2 and 3 are 98.6\%,98.0\% and 98.3\%, respectively. The minimum voltages for Cases 1, 2 and 3 are 0.993 p.u., 0.987 p.u. and 0.989 p.u., respectively. During the event, the gensets vary their generations for maintaining the energy balance in the grid. The event results in the changes of the 
system frequency and voltage. In all the cases, the variations of the dynamic variables stay within the permissible limits, signifying the secure operation of the grid is maintained.
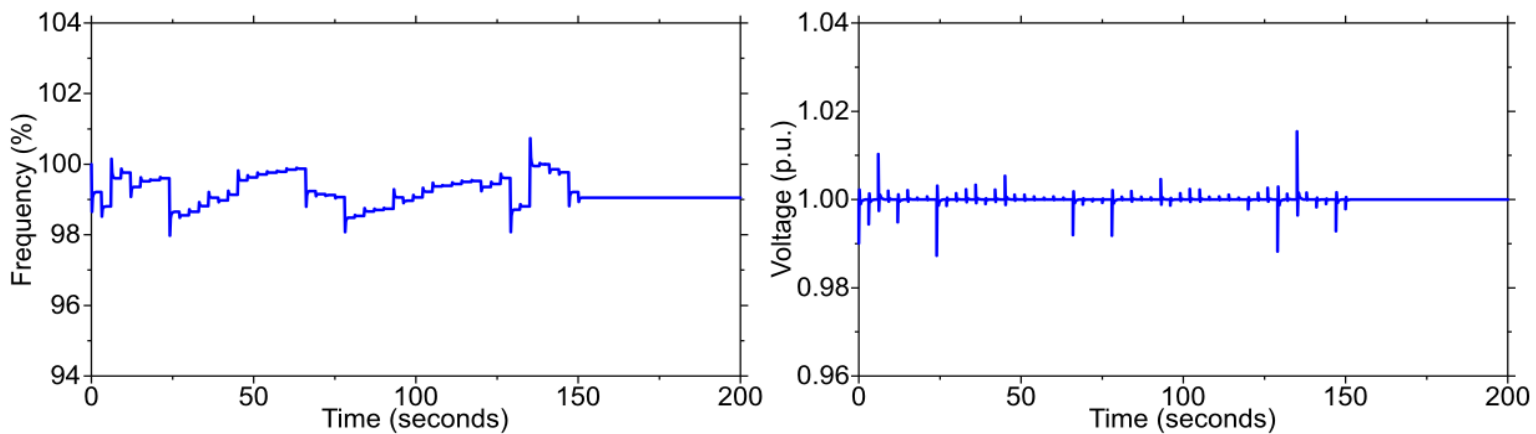

Figure 17. System frequency (left) and voltage (right) responses of Case 2 during Event 3

\subsubsection{Event 4: Sudden loss of generation from the genset}

The impact in relation to one of the operating gensets fully loses its generation at 2 seconds is examined. This event represents a critical condition to the normal grid operation, especially in Cases 2 and 3 with the already limited dynamic support in the grid. During the event, the PV system injection corresponds to $24.4 \%, 39.0 \%$ and $32.0 \%$ of the total online grid generation capacity in Cases 1, 2 and 3, respectively. For each case, the system frequency drops to the lowest at $97.96 \%, 96.03 \%$ and $96.02 \%$, respectively and increases progressively back to its steady-state. The finding is in good agreement with the frequency response reported in the work by Feilat et al. in [37] for the Jordanian power system. Meanwhile, the minimum system voltages for Cases 1, 2 and 3 are 0.978 p.u., 0.970 p.u. and 0.975 p.u., respectively. Despite the system frequency drops and voltage variations, the event neither leads to limit violation nor grid collapse in all the cases. It implies that the grid could sustain the loss of one genset with the PV system in the grid. The remaining operating genset ramps up its generation immediately with the governor action for maintaining the grid operation continuity. Thereby, the grid operator shall initiate the start-up of the standby genset for strengthening the grid security.

\subsection{PV system placement optimization}

The optimization potential at each prospective interconnection point is assessed with the aim of identifying the best PV system placement in the grid for active line losses minimization, grid voltage profile enhancement, and line reserve capacity improvement. All the interconnection points are nominated for the optimization since there is no violation of the voltage and line ampere loading limit. Figure 18 depicts the $A L L I, V I$ and $L C I$ determined for each interconnection scenario. Correspondingly, the MOPI for Scenarios 1, 2, 3 and 4 are $0.563,0.455,0.443$ and 0.543 , respectively. A smaller MOPI is desirable as it indicates a higher potential. Among the scenarios, Scenario 3 is discovered to be optimal for the PV system deployment. This is followed by Scenario 2 and Scenario 4. The result suggests prioritizing the deployment based on Scenario 3 in order to maximize the contribution of the PV system to the grid operation. Thereby, minimizing losses by $23.5 \%$, enhancing voltage by $0.04 \%$, and improving line reserve capacity by $0.9 \%$. Further, the comparison with Scenario 1 shows that the PV system interconnection at any of the three points is capable of enhancing the grid operation. Recognizing the different potentials at each point, performing optimization study for all the future interconnections is recommended for inclusion as a requirement in the RE policy.

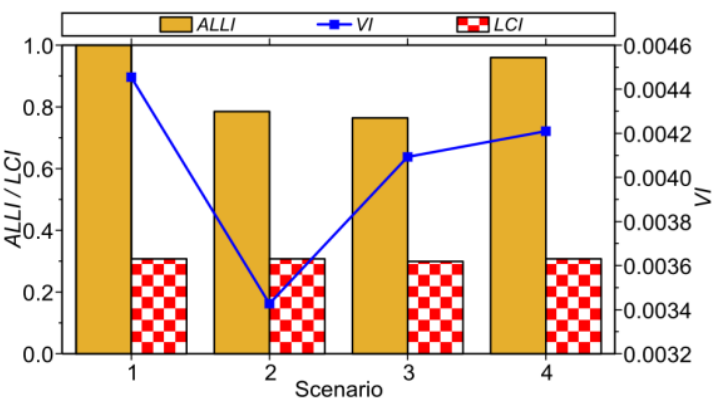

Figure 18. Performance indices of different interconnection scenarios 


\section{CONCLUSION}

In this paper, a conjoint assessment encompassing the performance of a $2 \mathrm{MWp}$ CdTe-based PV system designed (32\% penetration ratio relative to peak grid demand) and scenario-based interconnection impacts in an isolated $11 \mathrm{kV}$ 10-bus Bruneian microgrid was performed. The meteorological data of the site and potential generation of the PV system for 8,760 hours over the year were firstly computed using Meteonorm and PVsyst, respectively. The system performance was assessed according to IEC EN 61724 standards. The performance indices of the PV system at $Y f: 4.51 \mathrm{kWh} / \mathrm{kWp} / \mathrm{day}, Y r: 4.98$ hours/day and $P R$ : $90.6 \%$ demonstrate the high deployment potential under the meteorological condition of the site.

Corresponding to the PV system generation and multiple feeder-specific measured load profiles, the impacts of the PV system interconnection at each potential point were assessed in ETAP. The analysis comprised aspects of time-series power flow, short-circuit, and dynamic transient stability. Despite power flow changes in the grid, the power flow assessment with respect to time-varying demands and maximum PV system generation profile indicated grid operation enhancement in terms of loadability, line reserve capacity and operating efficiency, without violating voltage and line ampere loading limit. Nevertheless, at times of substantial mismatch between generation and demand, the synergy raised concerns on genset operation regarding underloading and PF limit violation. Proper genset sequencing for allocating an appropriate number of operating genset and reactive power management for inverters operating at permissible PF, are necessary.

While short-circuit analysis conforming to IEC 60909 standards revealed the PV system leads to a higher maximum fault current level up to $0.56 \%$, increased downstream fault current and the introduction of reverse fault current, it poses a minimal impact on the protection system operation. The existing protection devices and protection scheme were validated to remain adequate. The dynamic transient stability analysis evaluating the secure operation of the grid under the critical grid operating conditions presented the grid remained stable in the events of a sudden loss of generation from the PV system or genset, rapid PV system generation ramping down, and continuous PV system generation fluctuation. The most challenging circumstance was ascertained to be sudden generation loss of a genset with the already reduced system inertia and spinning reserve in the grid in adherence to the minimum genset loading threshold. In that case, the system frequency dropped to as low as $96.02 \%$. The optimal PV system placement was identified using MOPI to be Scenario 3, attaining $23.5 \%$ loss reduction, $0.04 \%$ voltage enhancement, and $0.9 \%$ line reserve capacity improvement. Based on the findings in the present study, the following recommendations are provided for RE planning and policymaking.

1. The systematic analysis concerning grid-connected PV system deployment shall include PV system performance and interconnection impact assessments based upon a detailed PV system model considering deployment conditions. Accordingly, a more complete and realistic analysis with a clear knowledge of the PV system design and specification could be delivered, which is beneficial for proper decision making and grid planning.

2. A minimum PV system performance requirement shall be specified for promoting high-efficiency system deployment. For instance, all the future proposed systems must exceed $P R$ of $80 \%$. The threshold shall be gradually increased with technological improvement. Acknowledging the variation of solar inverter performance across different capacities and models, the requirement of prioritizing the adoption of the inverter with the least operating losses shall be stipulated. Additionally, the proposed inverter shall be capable of operating within a wide range of PF. This capability is imperative in providing necessary support to suit grid operating requirements. The inverters operating at 0.95 overexcitation mode well adhere to the acceptable genset operating PF limit and reduce the reactive power generation burden of the gensets.

3. Recognizing locational dependence of the PV system interconnection impacts, in-depth assessment on various prospective points incorporating multiple feeder-specific measured load profiles shall be mandated in all interconnection proposals. It shall facilitate the understanding of realistic benefits and challenges associated with the interconnection at each point.

4. The impacts of reverse power flow in the grid shall require a comprehensive assessment instead of direct regard it as a negative indication. Its impacts are corresponding to its magnitude and the grid characteristic. It has been shown in the present study that the PV system deployment resulting in reverse power flow does not cause a violation of voltage and line ampere loading limit while bringing benefits to the grid.

5. Grid protection devices with directional elements shall be deployed in the case of having a larger shortcircuit capacity of the PV system resulting from potentially more PV system deployments in the future. The purpose is to mitigate protection device misoperation associated with the reverse fault current. 
Clearly, the multitude of findings in the study indicates a good prospect of the PV system deployment. The analysis could contribute to RE planning and policymaking for advancing energy transition. Additionally, the findings and recommendations could serve as a guide for future deployments, especially in ASEAN with a similar climate and expecting a proliferation of the PV system towards achieving the regional RE joint aim. The research on the PV system deployment from the financial perspective and the implementation of a grid-connected rooftop CdTe-based PV system under the local meteorological condition with field performance monitoring system for data collection and validation will be focused in future work.

\section{ACKNOWLEDGMENTS}

The authors wish to acknowledge Universiti Teknologi Brunei for the funding and the national utility company - Berakas Power Management Company Sdn Bhd for access to the technical data and the support provided in performing this research work.

\section{REFERENCES}

[1] UN. (2015). CHAPTER XXVII: ENVIRONMENT [Online]. Available: https://treaties.un.org/pages/ViewDetails.aspx?src=TREATY\&mtdsg_no=XXVII-7-d\&chapter=27\&clang=_en

[2] A. E. Raftery, A. Zimmer, D. M. Frierson, R. Startz, and P. Liu, "Less than $2^{\circ} \mathrm{C}$ warming by 2100 unlikely," Nature Climate Change, vol. 7, pp. 637-641, 2017.

[3] B. Ang and T. Goh, "Carbon intensity of electricity in ASEAN: Drivers, performance and outlook," Energy Policy, vol. 98, pp. 170-179, 2016.

[4] EDPMO. (2014), Brunei Darussalam Energy White Paper. 1-82. Available: http://memi.gov.bn/Shared\%20Documents/Publications/Energy\%20White\%20Paper\%202014.pdf

[5] BP. (2018), BP Statistical Review of World Energy 2018. 1-56. Available: https://www.bp.com/content/dam/bp/business-sites/en/global/corporate/pdfs/energy-economics/statisticalreview/bp-stats-review-2018-full-report.pdf

[6] EIDPMO. (2016), Brunei Darussalam Country Report. Energy Outlook and Energy Saving Potential in East Asia 2016, 79-90. Available: http://www.eria.org/RPR_FY2015_No.5_Chapter_3.pdf

[7] IRENA. (2017), Renewable Energy Rises Across Asia. IRENA Quarterly Q4 2017, 1-8. Available: https://www.irena.org/-/media/Files/IRENA/Agency/Quarterly/IRENA_Quarterly_2017_Q4.pdf

[8] N. Lidula, N. Mithulananthan, W. Ongsakul, C. Widjaya, and R. Henson, "ASEAN towards clean and sustainable energy: Potentials, utilization and barriers," Renewable Energy, vol. 32, pp. 1441-1452, 2007.

[9] J. Shuai, C.-f. Chen, J. Cheng, Z. Leng, and Z. Wang, "Are China's solar PV products competitive in the context of the Belt and Road Initiative?," Energy Policy, vol. 120, pp. 559-568, 2018.

[10] N. Ahmad and H. Byrd, "Empowering distributed solar PV energy for Malaysian rural housing: towards energy security and equitability of rural communities," International Journal of Renewable Energy Development, vol. 2, pp. 59-68, 2013.

[11] P. Peerapong and B. Limmeechokchai, "Optimal electricity development by increasing solar resources in dieselbased micro grid of island society in Thailand," Energy Reports, vol. 3, pp. 1-13, 2017.

[12] R. Pacudan, "Feed-in tariff vs incentivized self-consumption: Options for residential solar PV policy in Brunei Darussalam," Renewable Energy, vol. 122, pp. 362-374, 2018.

[13] C. Lao and S. Chungpaibulpatana, "Techno-economic analysis of hybrid system for rural electrification in Cambodia," Energy Procedia, vol. 138, pp. 524-529, 2017.

[14] A. Veldhuis and A. H. Reinders, "Reviewing the potential and cost-effectiveness of grid-connected solar PV in Indonesia on a provincial level," Renewable and Sustainable Energy Reviews, vol. 27, pp. 315-324, 2013.

[15] H. Kim and T. Y. Jung, "Independent solar photovoltaic with Energy Storage Systems (ESS) for rural electrification in Myanmar," Renewable and Sustainable Energy Reviews, vol. 82, pp. 1187-1194, 2018.

[16] A. M. Ismail, R. Ramirez-Iniguez, M. Asif, A. B. Munir, and F. Muhammad-Sukki, "Progress of solar photovoltaic in ASEAN countries: A review," Renewable and Sustainable Energy Reviews, vol. 48, pp. 399-412, 2015.

[17] S. Bhakta and V. Mukherjee, "Solar potential assessment and performance indices analysis of photovoltaic generator for isolated Lakshadweep island of India," Sustainable Energy Technologies and Assessments, vol. 17, pp. 1-10, 2016.

[18] D. A. Quansah, M. S. Adaramola, G. K. Appiah, and I. A. Edwin, "Performance analysis of different gridconnected solar photovoltaic (PV) system technologies with combined capacity of $20 \mathrm{~kW}$ located in humid tropical climate," International Journal of Hydrogen Energy, vol. 42, pp. 4626-4635, 2017.

[19] H. Lu and W. Zhao, "Effects of particle sizes and tilt angles on dust deposition characteristics of a ground-mounted solar photovoltaic system," Applied Energy, vol. 220, pp. 514-526, 2018.

[20] S. Yilmaz and F. Dincer, "Impact of inverter capacity on the performance in large-scale photovoltaic power plantsA case study for Gainesville, Florida," Renewable and Sustainable Energy Reviews, vol. 79, pp. 15-23, 2017.

[21] B. S. Kumar and K. Sudhakar, "Performance evaluation of $10 \mathrm{MW}$ grid connected solar photovoltaic power plant in India," Energy Reports, vol. 1, pp. 184-192, 2015.

[22] E. Zawilska and M. Brooks, "An assessment of the solar resource for Durban, South Africa," Renewable Energy, vol. 36, pp. 3433-3438, 2011. 
[23] S. Stökler, C. Schillings, and B. Kraas, "Solar resource assessment study for Pakistan," Renewable and Sustainable Energy Reviews, vol. 58, pp. 1184-1188, 2016.

[24] J. Urbanetz, P. Braun, and R. Rüther, "Power quality analysis of grid-connected solar photovoltaic generators in Brazil," Energy Conversion and Management, vol. 64, pp. 8-14, 2012.

[25] M. Hammad, M. S. Ebaid, G. Halaseh, and B. Erekat, "Large scale grid connected (20MW) photovoltaic system for peak load shaving in Sahab industrial district," Jordan Journal of Mechanical \& Industrial Engineering, vol. 9, pp. 45-59, 2015.

[26] Y. Wu, G. Ye, and M. Shaaban, "Analysis of impact of integration of large PV generation capacity and optimization of PV capacity: case studies in Taiwan," IEEE Transactions on Industry Applications, vol. 52, pp. 4535-4548, 2016.

[27] S. S. Refaat, H. Abu-Rub, A. P. Sanfilippo, and A. Mohamed, "Impact of grid-tied large-scale photovoltaic system on dynamic voltage stability of electric power grids," IET Renewable Power Generation, vol. 12, pp. 157-164, 2018.

[28] A. P. Kenneth and K. Folly, "Voltage rise issue with high penetration of grid connected PV," IFAC Proceedings Volumes, vol. 47, pp. 4959-4966, 2014.

[29] M. F. Nadeem Khan, T. N. Malik, and I. A. Sajjad, "Impact of time varying load models on PV DG planning," Journal of Renewable and Sustainable Energy, vol. 10, p. 035501, 2018.

[30] K. A. Baharin, N. A. Isa, C. K. Gan, and M. Shamshiri, "High PV penetration impact on European-based LV residential network," Telkomnika, vol. 16, pp. 1375-1382, 2018.

[31] G. Tevar, A. Gomez-Exposito, A. Arcos-Vargas, and M. Rodriguez-Montanes, "Influence of rooftop PV generation on net demand, losses and network congestions: A case study," International Journal of Electrical Power \& Energy Systems, vol. 106, pp. 68-86, 2019.

[32] Y. Hou, et al., "Impact on Voltage Rise of PV Generation in Future Swedish Urban Areas with High PV Penetration," in 2014 IEEE International Energy Conference (ENERGYCON), 2014, pp. 904-911.

[33] M. H. Athari, et al., "Time-Series Analysis of Photovoltaic Distributed Generation Impacts on a Local Distributed Network," in 2017 IEEE Manchester PowerTech, 2017, pp. 1-6.

[34] M. Kumar, P. Nallagownden, and I. Elamvazuthi, "Multi-objective PSO based optimal placement of solar power DG in radial distribution system," Journal of Electrical Systems, vol. 13, pp. 322-331, 2017.

[35] N. Barsoum and C. Z. Lee, "Simulation of power flow and protection of a limited bus grid system with injected solar power," Energy and Power Engineering, vol. 5, pp. 59-69, 2013.

[36] Y. N. L. de Marco, T. Zheng, and S. Nikolovski, "Overcurrent protection assessment with high PV penetration in a distribution network," International Journal of Renewable Energy Research, vol. 8, pp. 396-406, 2018.

[37] E. Feilat, S. Azzam, and A. Al-Salaymeh, "Impact of large PV and wind power plants on voltage and frequency stability of Jordan's national grid," Sustainable Cities and Society, vol. 36, pp. 257-271, 2018.

[38] S. R. Kumar, F. Gafaro, A. Daka, and A. Raturi, "Modelling and analysis of grid integration for high shares of solar PV in small isolated systems - a case of Kiribati," Renewable Energy, vol. 108, pp. 589-597, 2017.

[39] Meteonorm. [Online]. Available: https://meteonorm.com/en/

[40] PVsyst. [Online]. Available: https://www.pvsyst.com/

[41] Z. L. Chai, S. Ang, A. Khalil, M. A. Salam, and W. Voon, "Assessment of different strategies in optimizing network operation incorporating PV system," Indonesian Journal of Electrical Engineering and Informatics (IJEEI), vol. 7, pp. 639-649, 2019.

[42] F. Solar, "Recommended parametric descriptions of First Solar series 4 (v3) PV modules for use with PVsyst," 1.1 ed, 2017.

[43] J. Merten, J. Asensi, C. Voz, A. Shah, R. Platz, and J. Andreu, "Improved equivalent circuit and analytical model for amorphous silicon solar cells and modules," IEEE Transactions on Electron Devices, vol. 45, pp. 423-429, 1998.

[44] A. Mermoud and T. Lejeune, "Performance Assessment of a Simulation Model for PV Modules of Any Available Technology," in Proceedings of the 25th European Photovoltaic Solar Energy Conference, 2010, pp. 1-7.

[45] F. Solar, "PVsyst modeling guide for thin film technology ", 5 ed, 2016.

[46] CEC. (2019). Clean Energy Council install and supervise guidelines for accredited installers (13 ed.). Available: https://assets.cleanenergycouncil.org.au/documents/accreditation/grid-connected-solar-pv-systems-install-andsupervise-guidelines-for-accredited-installers-v13-2019.pdf

[47] M. Brennan, A. Abramase, R. W. Andrews, and J. M. Pearce, "Effects of spectral albedo on solar photovoltaic devices," Solar Energy Materials and Solar Cells, vol. 124, pp. 111-116, 2014.

[48] M. Lee, et al., "Accuracy of CdTe PV Energy Predictions Using Spectral Corrections," in 2017 IEEE 44th Photovoltaic Specialist Conference (PVSC), 2017, pp. 595-599.

[49] SMA, "Sunny Central 1000CP XT," 2.3 ed.

[50] BSI, Photovoltaic system performance monitoring — Guidelines for measurement, data exchange and analysis, 1st ed. London: British Standards Institution, 1998.

[51] ETAP. [Online]. Available: https://etap.com/

[52] S. Rehman and L. M. Al-Hadhrami, "Study of a solar PV-diesel-battery hybrid power system for a remotely located population near Rafha, Saudi Arabia," Energy, vol. 35, pp. 4986-4995, 2010.

[53] M. Boulaid, A. Tihane, R. Oaddi, A. Elfanaoui, K. Bouabid, and A. Ihlal, "Comparative performance assessment of mono crystalline, multi crystalline, and amorphous silicon grid-connected photovoltaic systems under actual climatic conditions of Agadir, Morocco," International Journal of Green Energy, vol. 14, pp. 1182-1191, 2017. 
[54] L. G. Monteiro, W. N. Macedo, P. F. Torres, M. M. Silva, G. Amaral, A. S. Piterman, B. M. Lopes, J. M. Fraga, and W. C. Boaventura, "One-year monitoring PV power plant installed on rooftop of Mineirão Fifa World Cup/Olympics football stadium," Energies, vol. 10, p. 225, 2017.

[55] C. E. B. E. Sidi, M. L. Ndiaye, M. El Bah, A. Mbodji, A. Ndiaye, and P. A. Ndiaye, "Performance analysis of the first large-scale (15 MWp) grid-connected photovoltaic plant in Mauritania," Energy Conversion and Management, vol. 119, pp. 411-421, 2016.

[56] A. Al-Otaibi, A. Al-Qattan, F. Fairouz, and A. Al-Mulla, "Performance evaluation of photovoltaic systems on Kuwaiti schools' rooftop," Energy Conversion and Management, vol. 95, pp. 110-119, 2015.

[57] S. Sundaram and J. S. C. Babu, "Performance evaluation and validation of $5 \mathrm{MWp}$ grid connected solar photovoltaic plant in South India," Energy Conversion and Management, vol. 100, pp. 429-439, 2015.

[58] M. Farhoodnea, A. Mohamed, H. Shareef, and H. Zayandehroodi, "Power quality analysis of grid-connected photovoltaic systems in distribution networks," Przeglad Elektrotechniczny (Electrical Review), vol. 02a/2013, pp. 208-213, 2013. 